in vivo $34: 3527-3532(2020)$

doi:10.21873/invivo.12194

\title{
Giant Intrathoracic Schwannoma: A Case Report
}

\author{
CORNEL SAVU ${ }^{1,2}$, VASILE GRIGORIE ${ }^{1}$, ALEXANDRU MELINTE ${ }^{1}$, CAMELIA DIACONU 2,3 , \\ LAURA ILIESCU 2,4, MIHAI DIMITRIU $^{2,5}$, IRINA BALESCU ${ }^{6}$ and NICOLAE BACALBASA ${ }^{2,7,8}$ \\ ${ }^{1}$ Department of Thoracic Surgery, "Marius Nasta" National Institute of Pneumophtisiology, Bucharest, Romania; \\ 2 "Carol Davila" University of Medicine and Pharmacy, Bucharest, Romania; \\ ${ }^{3}$ Department of Internal Medicine, Clinical Emergency Hospital of Bucharest, Bucharest, Romania; \\ ${ }^{4}$ Department of Internal Medicine, "Fundeni" Clinical Institute, Bucharest, Romania; \\ ${ }^{5}$ Department of Obstetrics and Gynecology, "Sf. Pantelimon" Emergency Clinical Hospital, Bucharest, Romania; \\ ${ }^{6}$ Department of Visceral Surgery, "Ponderas Academic Hospital", Bucharest, Romania; \\ ${ }^{7}$ Department of Visceral Surgery, Center of Excellence in Translational Medicine, \\ "Fundeni" Clinical Institute, Bucharest, Romania; \\ ${ }^{8}$ Department of Obstetrics and Gynecology, "I. Cantacuzino" Clinical Hospital, Bucharest, Romania
}

\begin{abstract}
Background/Aim: Thoracic neurogenic tumors are most frequently located in the posterior part of the mediastinum or on the chest wall, along the intercostal nerves. Schwannomas are very well tolerated for a long period, until the tumor reaches a large size and compression of the neighbouring mediastinal organs, chest wall or spine appears. The purpose of this article was to present a case of a giant right forth intercostal nerve Schwannoma, completely resected by a right antero-lateral thoracotomy. In addition, intrathoracic giant neurogenic tumors are a rarity. Case Report: The patient presented with only diminished tolerance to physical activity with no other obvious symptoms. Standard chest radiography revealed a well-defined opacity of subcostal intensity, occupying two thirds of the right hemithorax, forming a common body with the mediastinal shadow. Thoracic computed tomography $(C T)$ identified a $21 / 11 \mathrm{~cm}$ solid mass that compresses the right lung and the right main bronchus with both a solid component and a central liquid area. Open surgery was performed in order to remove the tumor, which was 20.5/12.5/9 cm in size and weighed 1,830 g, well defined, with no invasion of the adjacent organs, having a solidfibromatous aspect as well as a central necrotic area. The origin of the tumor was confirmed from the posterolateral part
\end{abstract}

This article is freely accessible online.

Correspondence to: Cornel Savu, MD, Ph.D., "Marius Nasta" Institute of Pneumonology, 90, Soseaua Viilor, 050152 Bucharest, Romania. Tel: +40 0213356910, e-mail: drsavu25@yahoo.com

Key Words: Schwannoma, anterolateral thoracotomy, giant neurogenic tumors, dumbbell tumor. of the forth intercostal nerve. Pathology examination and immunohistochemistry confirmed the diagnosis of a benign Schwannoma. Conclusion: Benign intrathoracic Schwannomas are asymptomatic for long periods and the main therapeutic option is complete surgical resection. The surgical approach, either open or video-assisted is dictated by the localisation of the tumor, local extension and most importantly the size of the neurogenic mass.

The incidence of neurogenic mediastinal tumors is between $12-21 \%$ of the total mediastinal tumors (1), being most of the time benign lesions (2). Neurogenic tumors are frequently found in the posterior mediastinum, intercostal space, thoracic sympathetic nerve or ganglion, thoracic vagus nerve and very rarely developed in the lung (3). Of all the posterior mediastinal masses, over $75 \%$ of cases are neurogenic tumors (4). Overall, benign neurogenic tumors represent $93.5 \%$ of cases and the malignant ones only $6.5 \%$ (5).

Benign neurogenic tumors are most often found on the intercostal or vagus nerves. Alongside neurofibromatosis, ganglioneuromas or paragangliomas, Schwannomas are the most common, found in $48 \%$ of cases (6). Schwannoma has several names in the literature such as neurilemmoma, neurilenoma or neuroma, with its origin in the Schwann cells. The first person to describe these cells was Theodor Schwann, a German physiologist, biologist and histologist (7).

Malignant neurogenic tumors are more often found in children or young adults and represent $67.2 \%$ of cases and rarely discovered at an adult age $(8,9)$. On the other hand, mediastinal localisation of a peripheral nerve cyst-tumor is extremely rare, $0.5-7 \%$ of cases, and malignant Schwannoma in $5 \%$ of cases, usually associated with Recklinghausen disease (10-12). 


\section{Case Report}

A 60-year-old male presented in our clinic for a diminished tolerance to physical activity in the last few weeks and mild dyspnea, with no other thoracic symptoms and associated cardiac or respiratory pathology. Standard chest radiography (Figure 1) revealed a well-defined, homogenous mass occupying two thirds of the right hemithorax forming a common body with the mediastinal shadow. Blood tests show a slightly elevated $\mathrm{pCO} 2$. Respiratory volume tests revealed a restrictive ventilator defect with significantly lower forced expiratory volume (FEV $1-0.981 / 58 \%$ ) and forced vital capacity (FVC $-1.711 / 64 \%$ ) then the predicted values.

Bronchoscopy studies identified compression of the posterior wall of the right main bronchus, which continued throughout the bronchial tree. Standard and contrast thoracic CT (Figure 2) confirmed the presence of a giant, $21 / 11 \mathrm{~cm}$ mass, occupying the entire right hemithorax, compressing the right lung and bronchial tree and moving the mediastinal organs towards the left side. The mass was mostly solid, homogenous, with a central liquid area suggesting necrosis, with no invasion of the neighbouring organs or chest wall.

Open surgery was performed by right anterolateral thoracotomy with access through the fifth intercostal space. Intraoperatively we discovered a well-defined tumor, adherent to the upper and middle lobe of the lung, compressing it. We identified a wide base for the tumor from the forth-intercostal space, with no local invasion, being relatively easy to detach from the adjacent lung with complete resection of the tumor. The mass was 20.5/12.5/9 $\mathrm{cm}$ in size and weighed $1,830 \mathrm{~g}$. After removal of the tumor, complete expansion of the lung was obtained.

Postoperative evolution of the patient was favourable, with no complications, with the patient being discharged after 7 days. Histopathological examination (Figure 3) macroscopically described a giant encapsulated tumor, with a yellow, macronodular structure and a large central cystic degeneration, with hematic contents and white areas with sclerotic aspect. Microscopically the tumor was surrounded by a thick, collagenous capsule that contains numerous capillary vessels and lymphoid follicles. Tumor contained fusiform Schwann cells, with no atypical cells or mitosis. Cells were distributed as fascicles in hypercelular areas (Antony A) with palisade aspect, alternating with hypocellular areas with myxoid or cystic degeneration (Antony B), with no signs of capsular invasion.

The final histopathological diagnosis was that of benign giant thoracic schwannoma. Immunohistochemistry tests for cytokeratin, vimentin and epidermal growth factor receptor (EGFR) were negative; however, tests were positive for S100 protein. These tests also confirmed our diagnosis of a benign intrathoracic schwannoma. Follow-up was made after 6 months and 1 year with excellent results, lung volume tests improved dramatically (FEV1 - 1.72 L-90\%; FVC - 2.48 L$92 \%$ ) and standard chest radiography was normal, with no sign of local recurrence.

\section{Discussion}

Neurogenic tumors represent the most common mediastinal neoplastic disease in children, found in $46.2 \%$ of cases, where as in adults in $11.2 \%$ of cases. Schwannomas make up a $25-34 \%$ of the total cases of neurogenic tumors (13). Some authors consider that benign schwannomas represent $48.3 \%$ of the total number of thoracic neurogenic tumors and that $6.71 \%$ of them go through malignant transformation (14). An intrathoracic neurogenic tumor is considered giant if it occupies more than half of the hemithorax, which is a rare occurrence (3). In the presented case the tumor occupied two thirds of the right hemithorax and was removed using an anterolateral thoracotomy, only large enough to excise the tumor but with some sacrifice to intraoperative visibility.

Regarding symptoms, most benign neurogenic tumors are asymptomatic (15). In the cases of giant neurogenic tumors there is no consensus regarding clinical diagnosis (3). Most adult patients ( $84 \%$ of cases) and children (60\% of cases) with neurogenic tumors are asymptomatic (13). Other authors consider that malignant neurogenic tumors are symptomatic in most cases in children $(76.4 \%$ of cases) and much less in adults (36.7\% of cases) (16). In addition, other authors consider that while malignant neurogenic tumors are mostly symptomatic, the benign ones are not, being well tolerated over long periods. (17).

According to some authors, there is no clinically significant difference between malignant or benign neurogenic tumors (18). However, due to the large size of the tumor, mediastinal compression can occur, especially the compression of the vena cava with secondary superior vena cava syndrome (19). In our case, the patient presented with only a decreased tolerance to physical activity with no other significant clinical signs. Even so, due to the large size of the tumor, differential diagnosis was between a benign schwannoma and a possible giant intercostal nerve neurofibroma.

Schwannomas appear especially between 20-50 years of age and has an equal distribution between genders. Microscopically there are two types of cell patterns: Anthony A (Schwann cells as palisades or the presence of Verocay bodies) and Anthony B (polymorphic Schwann cells with a free myxoid component) (20). Both patterns can be present at the same time in the same Schwannoma, as was the case with our patient. Schwannomas are lobulated tumors and sometimes present with central degeneration, and are formed outward from the nerve axis. Microscopically, solitary neurofibromas have a structure formed of spindle cells with wavy nuclei, with no cellular pleomorphism, with various 


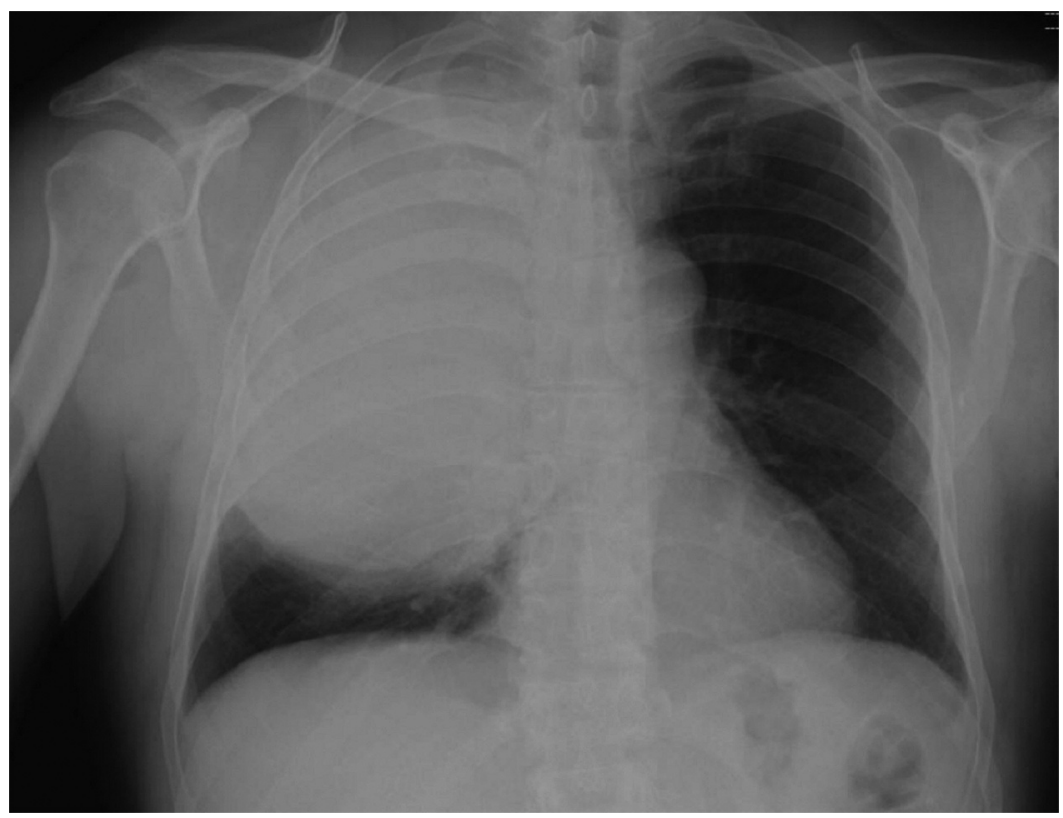

Figure 1. Standard thoracic radiography - mass in the right hemithorax.

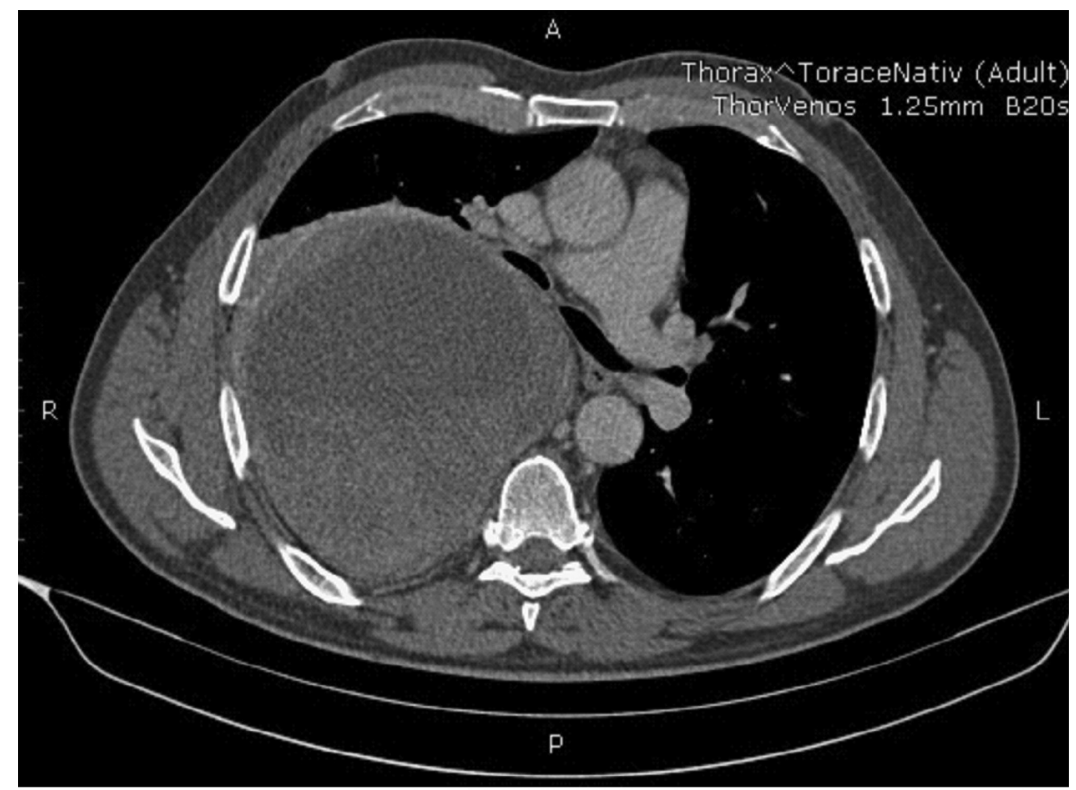

Figure 2. Thoracic computed tomography - mass in right hemithorax.

degrees of myxoid degeneration and the tumor is formed within the nerve axis (20).

Immunohistochemical differentiation between schwannomas and neurofibromas is extremely useful and based on the following markers: CD56, CD34, S100 protein, calretinin. Calretinin is much more specific to Schwannomas and is not found in neurofibromas, CD56 appears in 77\% of cases of Schwannomas whereas CD34 appears in $80 \%$ of cases of neurofibromas (21). On the other hand, immunoreactivity towards S100 protein seems to be the same in both schwannomas and neurofibromas. In our case, although very rare, given the size of the tumor, we considered a malignant 


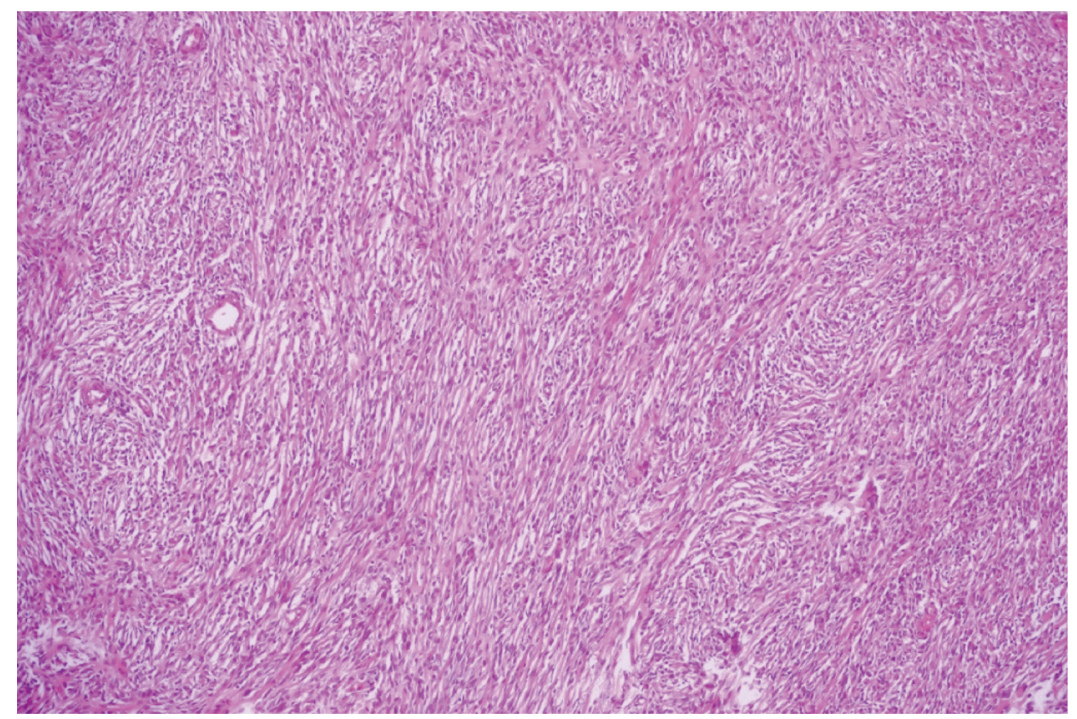

Figure 3. Histopathological microscopic view. Magnification $\times 20$.

transformation of the schwannoma, which usually presents as an epithelioid or angiosarcomatous transformation (22). Malignant Schwannomas are part of peripheral nerve sheath tumors. Some authors consider that $50 \%$ of malignant peripheral nerve sheath tumors appear in patients with type I Recklinghausen disease; however, there have been reported cases of malignant schwannomas in patients without the disease (23).

Some authors consider that the lifetime risk for developing malignant peripheral nerve sheath tumors in patients with type I neurofibromatosis is between $8-13 \%$ (24). Malignant peripheral nerve sheath tumors do not present a specific or sensitive marker for immunohistochemistry, most of the times being classified as a sarcoma, due to its origin and behaviour (25). In our case there were no histological elements or immunohistochemistry results to confirm a malignant transformation of the resected tumor.

Thoracic computed tomography (CT) and magnetic resonance imagining studies are the main imaging tools used for this type of pathology. Even so, it is difficult to determine whether a tumor is benign or malignant $(3,18)$. A series of authors attempted to differentiate between malignant and benign neurogenic tumors using a series of CT characteristics. Benign neurogenic tumors appear as round, well-defined masses of soft tissue with the presence of central cystic degeneration (20) whereas malignant tumors present with local invasion, bone tissue destruction, lung metastases or pleural effusions (26). However, in order to establish the extension of the lesion in the spine, magnetic resonance imaging studies are far superior to a thoracic CT (3).
Neurogenic tumors can be mistaken for solitary pleural fibrous tumors, chest wall tumors or other mediastinal masses $(27,28)$. CT-guided biopsy is useful in obtaining a preoperative diagnosis however, due to the low cell count in benign tumors, malignant or benign traits are not always obvious $(29,30)$.

The evolution of these tumors can lead to local complications such as compression of the neighbouring organs, bone destruction or growth in the spinal canal with associated medullar compression (1). A typical case of neurogenic tumor development is the one of a dumbbell tumor. Most authors agree that this type of tumor, especially if it is associated with bone destruction, requires a multidisciplinary team. For dumbbell tumors with spinal involvement, in order to prevent medullar lesions, some authors suggest using intraoperative spinal neurogenic motor evoked potential monitoring (31). For small dumbbell tumors a video-assisted approach is preferred and laminectomy is associated (32). For benign neurogenic tumors, complete surgical resection of the tumor is sufficient (17). The objectives of surgical removal are preventing local extension, obtaining a histopathological diagnosis, preventing malignant transformation and establishing the necessity of further treatment (14).

Minimal invasive surgery, according to some authors, is reserved for tumors that are smaller than $8 \mathrm{~cm}$ in diameter (33). Contraindications for this method are the involvement of the spinal artery or medullar extension of the tumor (16). However, a very large tumor, such as the one we presented, can be a major inconvenience, making minimally invasive surgery impossible to perform. The advantages of minimally invasive 
surgery compared to open surgery are obvious: reduces hospital stay, reduces postoperative pain, and reduces surgery duration and minimal postoperative blood loss (34-36).

According to some authors, video assisted surgery can be used even for malignant neurogenic tumors, with very satisfying results and minimal postoperative complications (37). Even so, a video assisted approach can present its own series of postoperative complications such as hoarseness, Claude Bernard Horner syndrome or brachial plexus lesions. Most specialists agree that minimally invasive surgery is reserved for cases with no local invasion or medullar extension $(31,38)$. Postoperative survival for thoracic neurogenic tumors is directly correlated with tumor size, whether the tumor is malignant or benign and if the mass is completely removed.

\section{Conclusion}

In benign giant neurogenic tumors, using open surgery, the golden standard of treatment is the complete removal of the mass. Due to these tumors most often being asymptomatic, early discovery is based on routine chest radiographies. The surgical approach, open or video assisted, is dictated by tumor placement, local extension and most importantly, tumor size.

\section{Conflicts of Interest}

The Authors declare no conflicts of interest regarding this study.

\section{Authors' Contributions}

CS, VG, AM performed the surgical procedure; NB, CS, MD, IB reviewed literature data, $\mathrm{CD}$, $\mathrm{LI}$ preoperative investigation the patient, IB, NB CS prepared the draft of the manuscript, CS was advisor of the surgical procedures CS, NB reviewed the final version of the manuscript. The Authors read and approved the final version of the manuscript.

\section{References}

1 Duwe BV, Sterman DH and Musani AI: Tumors of the mediastinum. Chest 128(4): 2893-2909, 2005. PMID: 16236967. DOI: $10.1378 /$ chest.128.4.2893

2 Strollo DC, Rosado-de-Christenson ML and Jett JR: Primary mediastinal tumors: part II. Tumors of the middle and posterior mediastinum. Chest 112(5): 1344-1357, 1997. PMID: 9367479. DOI: $10.1378 /$ chest.112.5.1344

3 Wang J, Yan J, Ren S, Guo Y, Gao Y and Zhou L: Giant neurogenic tumors of mediastinum: report of two cases and literature review. Chin J Cancer Res 25(2): 259-262, 2013. PMID: 23592909. DOI: 10.3978/j.issn.1000-9604.2013.03.09

4 Yamaguchi M, Yoshino I, Fukuyama S, Osoegawa A, Kameyama T, Tagawa T and Maehara Y: Surgical treatment of neurogenic tumors of the chest. Ann Thorac Cardiovasc Surg 10(3): 148-151, 2004. PMID: 15312009.
5 Ardissone F, Andrion A, D'Alessandro L, Borasio P and Maggi G: Neurogenic intrathoracic tumors. A clinicopathological review of 92 cases. Thorac Cardiovasc Surg 34(4): 260-264, 1986. PMID: 2429396. DOI: 10.1055/s-2007-1020424

6 Akyildiz EU and Yalcinkaya U: Thoracic neurogenic tumors: A clinicopathologic evaluation of 42 cases. Neurology Asia 20(1): 59-63, 2015.

7 Thomas TA: Theodor Schwann: A founding father of biology and medicine. In History of medicine. Curr Med Issues 15: 299301, 2017. DOI: $10.4103 / \mathrm{cmi} . c m i \_81 \_17$

8 Ribet ME and Cardot GR: Neurogenic tumors of the thorax. Ann Thorac Surg 58(4): 1091-1095, 1994. PMID: 7944757. DOI: 10.1016/0003-4975(94)90464-2.

9 Hoover EL, Hsu HK, Dressler C, Fani K, Webb H, Ketosugbo A and Kharma B: Neuroblastoma: a rare primary intrathoracic neurogenic tumor in adults. Tex Heart Inst J 15(2): 107-112, 1988. PMID: 15227261.

10 Reeder LB: Neurogenic tumors of the mediastinum. Semin Thorac Cardiovasc Surg 12(4): 261-267, 2000. PMID: 11154721. DOI: $10.1053 /$ stcs.2000.16738

11 Marchevsky AM: Mediastinal tumors of peripheral nervous system origin. Semin Diagn Pathol 16(1): 65-78, 1999. PMID: 10355655.

12 Grillo HC, Ojemann RG, Scannell JG and Zervas NT: Combined approach to "dumbbell" intrathoracic and intraspinal neurogenic tumors. Ann Thorac Surg 36(4): 402-407, 1983. PMID: 6625735. DOI: $10.1016 / \mathrm{s} 0003-4975(10) 60477-8$

13 Takeda S, Miyoshi S, Minami M and Matsuda H: Intrathoracic neurogenic tumors--50 years' experience in a Japanese institution. Eur J Cardiothorac Surg 26(4): 807-812, 2004. PMID: 15450577. DOI: 10.1016/j.ejcts.2004.07.014

14 Bicakcioglu P, Demirag F, Yazicioglu A, Aydogdu K, Kaya S and Karaoglanoglu N: Intrathoracic neurogenic tumors. Thorac Cardiovasc Surg 62(2): 147-152, 2014. PMID: 23613143. DOI: $10.1055 / \mathrm{s}-0033-1343898$

15 Schmezer A, Reinosch W, Laqua D and Bahr R: Thoracic neurinoma: a rare tumor of the posterior mediastinum. Chirurg 67(1): 90-92, 1996. PMID: 8851682.

16 Riquet M, Mouroux J, Pons F, Debrosse D, Dujon A, Dahan M and Jancovici R: Videothoracoscopic excision of thoracic neurogenic tumors. Ann Thorac Surg 60(4): 943-946, 1995. PMID: 7574999. DOI: 10.1016/0003-4975(95)00487-6.

17 Shields TW and Reynolds M: Neurogenic tumors of the thorax. Surg Clin North Am 68(3): 645-668, 1988. PMID: 3375959. DOI: 10.1016/s0039-6109(16)44538-x.

18 Kawaguchi T, Kawai N, Watanabe T, Yasukawa M, Morita K, Ohbayashi $\mathrm{C}$ and Tojo T: Primary intrathoracic malignant neurogenic tumor: report of three cases and comparison with benign neurogenic tumors resected at our institution. Surg Case Rep 1(1): 6, 2015. PMID: 26943374. DOI: 10.1186/s40792-0140013-1.

19 Galie N, Vasile R, Savu C, Petreanu C, Grigorie V and Tabacu E: Superior vena cava syndrome - surgical solution--case report. Chirurgia (Bucur) 105(6): 835-838, 2010. PMID: 21355182.

20 Pavlus JD, Carter BW, Tolley MD, Keung ES, Khorashadi L and Lichtenberger JP, III: Imaging of thoracic neurogenic tumors. AJR Am J Roentgenol 207(3): 552-561, 2016. PMID: 27340927. DOI: 10.2214/AJR.16.16018.

21 Park JY, Park H, Park NJ, Park JS, Sung HJ and Lee SS: Use of calretinin, CD56, and CD34 for differential diagnosis of 
schwannoma and neurofibroma. Korean J Pathol 45: 30-35, 2011. DOI: 10.4132/KoreanJPathol.2011.45.1.30

22 Woodruff JM, Selig AM, Crowley $\mathrm{K}$ and Allen PW: Schwannoma (neurilemoma) with malignant transformation. A rare, distinctive peripheral nerve tumor. Am J Surg Pathol 18(9): 882-895, 1994. PMID: 8067509. DOI: 10.1097/00000478199409000-00003.

23 Angelopoulos E, Eleftheriou K, Kyriakopoulos G, Athanassiadi $\mathrm{K}$, Rontogianni D and Routsi C: A giant intrathoracic malignant schwannoma causing respiratory failure in a patient without von Recklinghausen's disease. Case Rep Med 2016: 2541290, 2016. PMID: 27118974. DOI: 10.1155/2016/2541290.

24 Evans DG, Baser ME, McGaughran J, Sharif S, Howard E and Moran A: Malignant peripheral nerve sheath tumours in neurofibromatosis 1. J Med Genet 39(5): 311-314, 2002. PMID: 12011145. DOI: 10.1136/jmg.39.5.311

25 Rodriguez FJ, Folpe AL, Giannini C and Perry A: Pathology of peripheral nerve sheath tumors: diagnostic overview and update on selected diagnostic problems. Acta Neuropathol 123(3): 295319, 2012. PMID: 22327363. DOI: 10.1007/s00401-012-0954-z.

26 Lee JY, Lee KS, Han J, Yoon HK, Kim TS, Han BK, Kim J and Shim YM: Spectrum of neurogenic tumors in the thorax: CT and pathologic findings. J Comput Assist Tomogr 23(3): 399-406, 1999. PMID: 10348446. DOI: 10.1097/00004728-19990500000014.

27 Pirvu A, Angelescu D and Savu C: Localized fibrous tumor of the pleura an unusual cause of severe hypoglycaemia. Case report. Rev Med Chir Soc Med Nat Iasi 120(3): 628-630, 2016. PMID: 30142262.

28 Savu C, Melinte A, Balescu I and Bacalbasa N: Azygos vein aneurysm mimicking a mediastinal mass. In Vivo 34(4): 21352140, 2020. PMID: 32606194. DOI: 10.21873/invivo.12019

29 Kumar S, Rafiq MU, Ahamed I, Ansari J and Cowen ME: Asymptomatic giant thoracic schwannoma. Ann Thorac Surg 82(3): e26, 2006. PMID: 16928479. DOI: 10.1016/j.athoracsur.2006. 06.034

30 Savu C, Melinte A, Posea R, Galie N, Balescu I, Diaconu C, Cretoiu D, Dima S, Filipescu A, Balalau C and Bacalbasa N: Pleural solitary fibrous tumors-a retrospective study on 45 patients. Medicina (Kaunas) 56(4): 2020. PMID: 32316178. DOI: $10.3390 /$ medicina56040185
31 Hosking MP, Mongan PD and Peterson RE: Removal of a large intrathoracic tumor in a child: neurogenic motor-evoked potential monitoring of spinal cord integrity and anesthetic management. Anesth Analg 74(3): 460-463, 1992. PMID: 1539828. DOI: 10.1213/00000539-199203000-00023

32 Li Y, Wang B, Lv G and Li L: Thoracoscopy-assisted mini-open approach for resection of neurogenic tumors arising at the thoracic apex. Int J Clin Exp Med 10(3): 5175-5181, 2017.

33 Liu HP, Yim AP, Wan J, Chen H, Wu YC, Liu YH, Lin PJ and Chang $\mathrm{CH}$ : Thoracoscopic removal of intrathoracic neurogenic tumors: a combined Chinese experience. Ann Surg 232(2): 187190, 2000. PMID: 10903595. DOI: 10.1097/00000658-20000 8000-00006

34 Han PP and Dickman CA: Thoracoscopic resection of thoracic neurogenic tumors. J Neurosurg 96(3 Suppl): 304-308, 2002. PMID: 11990839. DOI: 10.3171/spi.2002.96.3.0304

35 Yang C, Zhao D, Zhou X, Ding J and Jiang G: A comparative study of video-assisted thoracoscopic resection versus thoracotomy for neurogenic tumours arising at the thoracic apex. Interact Cardiovasc Thorac Surg 20(1): 35-39, 2015. PMID: 25288101. DOI: 10.1093/icvts/ivu328

36 Yang C, Zhao D, Zhang P, Fei K and Jiang G: Intrathoracic neurogenic tumor with malignant transition-20 years operation experience in a medical center of China. Neurosci Lett 637: 195200, 2017. PMID: 27818351. DOI: 10.1016/j.neulet.2016.11.010

37 Fraga JC, Rothenberg S, Kiely E and Pierro A: Video-assisted thoracic surgery resection for pediatric mediastinal neurogenic tumors. J Pediatr Surg 47(7): 1349-1353, 2012. PMID: 22813795. DOI: $10.1016 /$ j.jpedsurg.2012.01.067

38 Horvat T, Savu C, Motas C and Tetu M: Pneumopericardium-complication of an unknown tuberculosis in a HIV positive patient. Eur J Cardiothorac Surg 26(5): 1043, 2004. PMID: 15519206. DOI: $10.1016 / j$.ejcts.2004.08.014

Received August 16, 2020

Revised August 27, 2020

Accepted September 7, 2020 